\title{
CEREALS AS FOOD
}

$\mathrm{T}$ HE fourth of the series of symposia on the nation's food arranged by the Society of Chemical Industry took place on October 29. The subject was "Cereals as Food".

The first paper, contributed by R. G. Booth, R. H. Carter, C. R. Jones and T. Moran, dealt with the "Chemistry of Wheat and Wheat Products". It consisted of a review of the literature, supplemented by estimations carried out by the authors on analyses of the wheat 'berry' as a whole and its separate constituents. The paper showed the wide variations that exist, depending upon the variety and cultural conditions of the wheat, but it is equally clear that many of the figures quoted in the literature are based on unsatisfactory analytical methods. Figures were given for the phytin and vitamin contents of wheat and flours of different extraction, and a large section of the paper dealt with the separation of the different fractions of wheat during milling.

This led logically to an analysis of high-extraction flours including National Wheatmeal. According to the authors, wheatmeal can be classified as rational or irrational meals depending upon how far the proportions of the different offal stocks in the meal are equal to, or are in excess of, the amounts present in whole wheat. National Wheatmeal is a rational meal, but the authors showed that, provided white flour continues to be milled, an 85 per cent extraction meal superior to National Wheatmeal could be produced. This is clearly a question to be considered after the War.

A. L. Bacharach and D. W. Kent-Jones followed with a paper on "The Nutrient Analysis of Bread". They first pointed out that flour as bread alone contributes something like 20 per cent of our total intake of calories and 20 per cent of our intake of proteins ; in all forms, including cakes, puddings, etc., these figures are increased to about 35 per cent. Incidentally, they showed that, in terms of calories and protein combined, bread is far and away the cheapest foodstuff. The authors then considered the effects of phytin in immobilizing calcium, and attempted a calculation of the available calcium in white flour and National Wheatmeal, on the basis that the salts formed are either the tri- or hexacalcium phytates. They pointed out, however, that this at best could only be a rough guide because of the complicating effects of magnesium on the precipitation of phytate. Their figures gave a quantitative justification for the $7 \mathrm{oz}$. and $14 \mathrm{oz}$. of calcium carbonate per sack of white flour and National Wheatmeal that the Medical Research Council recently recommended. It should be pointed out, however, that recent work has shown that most of the phytin can be hydrolysed by suitable conditions of baking, so that the higher amount for National Wheatmeal may not be necessary.

The authors also outlined the proposals in the United States for the fortification of white flour which would make $B_{1}$, nicotinic acid, riboflavin and iron compulsory, with calcium and vitamin $D$ optional. The maximum amounts proposed for the first four factors would make the flour the equivalent of wholemeal bread. Mr. Bacharach and Dr. KentJones suggested that the fortification of white flour should be extended to include iron as well as $B_{1}$ and calcium.
H. C. Moir had a difficult task in his paper on "The Composition and Nutritive Value of Oats and Oatmeal". The literature on this particular cereal is scattered and scanty, but the author succeeded in assembling data which should be of great value as a source of reference; there would, however, appear to be many anomalies; for example, the fact that the contents of tryptophase, lysine and histidine are greater in flaked oats as against whole oats. Mr. Moir emphasized that in view of the high protein, fat, iron and $B_{1}$ of oats, it is clearly an important human food. In the preparation of porridge the loss of $B_{1}$ is only 5-10 per cent, but with oatcakes the loss is 35 per cent, due presumably to the added sodium bicarbonate reducing the acidity. The question of phytin in oatmeal was also discussed, and it was pointed out that when porridge is properly prepared, that is, by soaking overnight, the inorganic phosphorus would be increased. The suggestion that oatmeal aggravates gout and rheumatic conditions was summarily dismissed.

The final paper, by W. P. Ford, "The Composition and Nutritive Value of Cereals other than Wheat and Oats", dealt with the remaining cereals-maize, rice, rye and barley. Maize contains 8-10 per cent of germ with a fat content in the germ of about 30 per cent. It is deficient in calcium, magnesium, iron and phosphorus as compared with wheat, but the protein contents of whole-maize and wheat are apparently equal.

The author described the changes in vitamin $B_{1}$ consequent upon de-husking, winnowing and polishing rice and showed why, except as a source of easily digestible carbohydrate, polished rice is the least valuable of all the cereals. He also mentioned the interesting fact that in the middle of the eighteenth century up to 42 per cent of rye was included in bread flour in Great Britain. German rye often contains 20-30 per cent of white flour, while American bread of the same name never contains less than 66 per cent.

In the discussion that followed, Dr. Green emphasized the importance, in cereal research, particularly in its nutritional aspects, of using material of known history and origin. This was supported by Mr. Bacharach, who, after pointing out the wide variations in individual chemical characteristics found in cereals, suggested that after the War at least, an organized attack should be made on all food stuffs, in order to collect precise and comprehensive analytical data.

Mr. Bacharach also stressed the need for further work on the availability of the different elements including calcium and iron, and went so far as to suggest that instead of protein figures for foods the individual amino-acids might be estimated.

In the papers and the discussion two points stood out : (1) the frequent references made to the analytical tables of McCance and Widdowson; (2) the unanimous view that much work has still to be carried out befor $\theta$ we have anything like a factual picture of the chemistry of cereals, even wheat. Perhaps for this reason the excursions into the nutritional field were generally extremely tentative. The chemist does not dogmatize without the facts. This alone is a guarantee of the value of these discussions on the nation's food. 